\title{
PHYSIOTHERAPY FOR THE SEQUELAE OF PHYSICAL TORTURE: UGANDA'S EXPERIENCE
}

\author{
AUTHOR: MR. MAYANJA FRED
}

\section{ABSTRACT}

The paper discusses the African Centre for treatment and rehabilitation of torture victims (ACTV) which was established in Uganda in 1993. The ACTV is a nongovernmental organisation offering treatment to the victims of torture. Professional staff at the centre include a physiotherapist, clinical psychologist, social worker, psychiatrist and psychiatric nurses. Specialised medical services outside of these areas that may be required, are provided by outside specialists.

Torture commonly involves both physical and psychological abuse and is often administered by individuals on behalf of an institution or organisation with the aim of punishing or intimidating a victim or attempting to obtain information from a victim. Physical torture may involve beatings, kickings, tyings, suspensions in forced positions, hard labour and other such physical abuse.

Apart from offering treatment and rehabilitation services the ACTV aims to raise awareness in the public arena concerning the plight of torture victims through workshops and seminars conducted in hospitals, schools and other institutions. Services are carried out both at the centre and in the community where satellite centres have been established. Referrals to the ACTV come from a wide variety of sources including, hospitals, human rights institutions, community leaders and self-referral.

From July to December 1997 the physiotherapist working at the centre conducted a survey of clients referred to the ACTV. During this period 309 people were referred to the centre; $45 \%$ male and $55 \%$ female. (See table below)

In this survey approximately $90 \%$ of the clients were referred for physiotherapy and $10 \%$ were referred to other specialists. It was reported that $97 \%$ of the victims showed improvement following treatment although the criteria for this are not discussed.

An emphasis regarding the respectful and ethical handling of clients is emphasised throughout the paper. For example not pursuing a particular line of questioning should the client not want to answer a particular question; avoiding the use of equipment that may remind the client of their torture (eg. ropes and certain electrotherapy apparatus), and listening carefully to the client's concerns regarding their treatment.

\begin{tabular}{|c|l|c|}
\hline Number & \multicolumn{1}{|c|}{ Condition } & \multicolumn{1}{c|}{ Percentage } \\
\hline 1. & Bachache & $26.3 \%$ \\
\hline 2. & Cervical pain & $3.7 \%$ \\
\hline 3. & Chest pain & $13.4 \%$ \\
\hline 4. & Upper limb pains & $11.8 \%$ \\
\hline 5. & Lower limb pains & $4.0 \%$ \\
\hline 6. & Numbness/parasthesia & $1.8 \%$ \\
\hline 7. & Sciatica & $1.2 \%$ \\
\hline 8. & Oedema & $0.2 \%$ \\
\hline 9. & Amputation & $1.0 \%$ \\
\hline 10. & Fractures & $3.1 \%$ \\
\hline 11. & Poor breathing & $6.2 \%$ \\
\hline 12. & Muscle weakness & $10.3 \%$ \\
\hline 13. & General muscle pain & $5.3 \%$ \\
\hline 14. & Joint pains & $4.1 \%$ \\
\hline 15. & Joint stiffness & $1.5 \%$ \\
\hline 16. & Pelvic inflammatory disease & 0.3 \\
\hline 17. & Poor posture & $0.1 \%$ \\
\hline 18. & Facial palsy & \\
\hline
\end{tabular}

